Article

\title{
A Developmental Disorder of Signed Language Production in a Native Deaf Signer of ASL
}

\author{
David Quinto-Pozos * and Frances Cooley \\ Department of Linguistics, University of Texas at Austin, Austin, TX 78713, USA; cooley.frances@utexas.edu \\ * Correspondence: davidqp@austin.utexas.edu
}

Received: 1 August 2020; Accepted: 1 October 2020; Published: 21 October 2020

\begin{abstract}
Evidence for a Developmental Language Disorder (DLD) could surface with language processing/comprehension, language production, or a combination of both. Whereas, various studies have described cases of DLD in signing deaf children, there exist few detailed examples of deaf children who exhibit production issues in the absence of processing or comprehension challenges or motor deficits. We describe such a situation by detailing a case study of "Gregory", a deaf native signer of American Sign Language (ASL). We adopt a detailed case-study methodology for obtaining information from Gregory's family and school, which we combine with linguistic and non-linguistic data that we collected through one-on-one sessions with Gregory. The results provide evidence of persistent issues with language production (in particular, atypical articulation of some phonological aspects of signs), yet typical comprehension skills and unremarkable fine-motor motor skills. We also provide a snapshot of Gregory's rich linguistic environment, which we speculate, may serve to attenuate his production deficit. The results of this study have implications for the provision of language services for signing deaf children in schools and also for language therapists. We propose that language therapists who are fluent in signed language be trained to work with signing children.
\end{abstract}

Keywords: expressive language disorder; phonology; comprehension; motor skills

\section{Introduction}

A growing body of research on signing deaf and hard of hearing (DHH) children with developmental language disorder (DLD) has revealed that signed language disorders exist among the population of children who are exposed to a signed language in childhood. The studies include a variety of DHH children, and they have been presented in the form of case-study reports (Morgan et al. 2007; Woll and Morgan 2012; Quinto-Pozos et al. 2013, 2017) and group studies (Mason et al. 2010; Herman et al. 2014; Marshall et al. 2013, 2015). Across the studies, deficits have been noted for deaf children with a signed language impairment in syntax and morphology (Morgan et al. 2007; Mason et al. 2010; Marshall et al. 2015), narrative abilities (Herman et al. 2014), and the use of the signing space for topographic descriptions, such as the use of classifier signs to indicate spatial relationships between referenced entities (Morgan et al. 2007; Marshall et al. 2015; Quinto-Pozos et al. 2013). There have been mixed results for vocabulary and semantics (Marshall et al. 2013). Some of these writings adopted the conceptual framework of specific language impairment (SLI) to refer to the children's deficits, although there has been notable variation in the profiles of the DHH children across the studies. We adopt the term DLD throughout this manuscript, following recent writings that suggest that a change in labels is merited (Bishop et al. 2017; Bishop 2017).

While parallels with spoken language development and hearing children with DLD have been made, there appear to be some differences in the manifestation of DLD across modalities. In comparing signed language disorders (deaf children) to spoken language disorders (hearing children), similarities have been made with respect to syntax, morphology, and narrative abilities. In this paper, we have 
not reviewed these studies in detail, but the reader is directed to the studies reported above. The area of phonology, however, has not yielded strong examples of similar types of markers for DLD across modalities (e.g., weaknesses with phonological awareness correlated with SLI). We discuss phonology in more detail below. Additionally, a developmental signed language disorder might also manifest with regard to the use of the signing space, such as for topographic purposes (i.e., to describe the locations of entities with respect to each other), which also involves perspective taking (Quinto-Pozos et al. 2013).

Whereas, the last decade has seen an increase in the studies of developmental signed language disorder, reported studies of language intervention are rare. One exception is a recent intervention study of an ASL-signing deaf child diagnosed with SLI (Kelley and McCann 2020). In that intervention study, Kelley and McCann report on the use of a single-subject multiple baseline across behaviors design. The intervention utilized focused stimulation and recasting in structured play sessions during weekly meetings, focusing on the production of verbs modifications and pronouns in space. The approach was reported to achieve some success, even though the intervention period was cut short due to COVID-19 in-person restrictions on research.

\subsection{Language Production}

One topic that has been addressed minimally is the extent to which school-aged deaf children articulate their signs clearly, with all features of a sign represented (but see Meier 2006 for a review of toddler and young child production abilities). One notable exception comes from researchers working on British Sign Language (BSL) (Marshall et al. 2006; Mann et al. 2010; Mason et al. 2010), who designed a non-sign reproduction task to examine deaf children's productions in phonologically simple-to-complex signs. Complexity was operationalized using phonological handshapes (marked versus unmarked, such as those that are more commonly represented versus those that are less frequent in use) and movements (single path movement or hand internal plus path movement combined). Over multiple studies, the non-sign repetition task was used with deaf children (ages 4-11 years), both with- and without-SLI. The studies uncovered correlations between repetition accuracy and age, and repetition accuracy and degree of complexity. The studies also echoed results of work on deaf toddlers. In particular, handshape and hand-internal movement are more difficult for children than path movement.

The BSL researchers also wondered whether the non-sign repetition task would serve as a useful tool for identifying deaf signing children with SLI. Interestingly, in a group study of BSL-signing deaf children with SLI (Mason et al. 2010), only a minority of the children (slightly less than one-third) performed poorly on the test. This was unexpected as non-word repetition is a common resource used to diagnose hearing children suspected of exhibiting SLI (Conti-Ramsden and Kesketh 2003). Based on the results of the group study one might suggest that impaired production of phonology may not be as reliable of a marker of developmental signed language disorder as one might expect. Marshall and Morgan (2016) suggest that this may be due to the greater number of degrees of freedom in signs compared to spoken language words (i.e., signs are formed by more possible combinations of handshapes, movements, and locations in comparison to the typical combinations of consonants and vowels in spoken languages).

In addition to the work conducted on BSL-signing children, a group of researchers in the U.S. has also been working on questions of developmental signed language disorders. For example, Quinto-Pozos et al. (2011) noted that language and learning professionals who work with DHH children report that some children expected of developing atypically demonstrate sloppy or lazy signing-seemingly a result of poor articulation of the features of signed language phonology. One question, then, is what degree of articulation problems constitutes typical signing, versus reflecting a language impairment? Another group has examined this question with regard to deaf children diagnosed with autism spectrum disorder (ASD).

A growing body of work has addressed atypical features of language-production for $\mathrm{DHH}$ children with ASD. Among those topics include, the use of facial expressions and non-manual signals 
(Denmark 2011; Denmark et al. 2014), pronoun use (Shield et al. 2015), echolalia (Shield et al. 2017), praxis (Shield et al. 2017), and hand/palm orientation errors (Shield and Meier 2012). Of particular relevance for the current work is the Shield et al. (2017) study of praxis, which found that DHH with ASD differed most notably from an adult sign model in so-called manner features. In that study, Shield and colleagues described a small number of manner features, in comparison with the sign model, including: (1) movement differences and joint usage, (2) use of a circuitous/indirect path to complete a movement, hesitation during a movement, or completion of the movement too quickly or in fewer steps, (3) pace differences (faster/slower) in comparison with the model, or (4) extra movements at the end of a movement sequence, involving both hands in the movement, or repeating a movement multiple times. Children with more severe ASD exhibited a larger number of these manner features of language production, and they also had poorer scores on a test of ASL comprehension. A separate study of praxis performance during fingerspelling also revealed differences between DHH children with ASD and typically-developing children regarding language comprehension (Bhat et al. 2017).

\subsection{Considering Language Use in the Social and Educational Environment}

DHH children are typically educated in mainstream schools (where hearing peers also attend) or in schools/programs for DHH students (i.e., where only deaf or hard of hearing peers attend or else concentrations of DHH students can be found). In various countries (e.g., the United Kingdom or the United States), the vast majority of DHH children currently attend mainstream programs. This pattern has been true for the past few decades, whereas in the 1970s and earlier most DHH children in these countries were educated in state-funded residential schools for the deaf. Teachers and instructional professionals at schools might use signed language, spoken language, or a mix of the two for instruction.

In recent decades in the U.S., multiple residential schools for the deaf have adopted policies (either formal or informal) supporting ASL use, both for instruction and for general communication while at school (e.g., in the school hallways, the cafeteria, the school grounds, etc.). It is important to mention that such schools often also support the use of spoken language for children who might benefit from such exposure, especially in specific environments (e.g., speech language therapy sessions), if a child wishes to speak while on campus grounds, or if a parent is encouraging their child to use her voice for communication.

Schools for the deaf that encourage signed language use can be the source of rich language input for DHH children with DLD. In such schools in the U.S., ASL is used by adults regularly (or, in some cases, exclusively) for everyday communication. In recent years, the percentage of Deaf teachers and language/developmental professionals has increased (see (Suggs 2018) for survey data). Many of these professional school staff members have been signing for their entire lives or since they were in school with other deaf peers. Additionally, there has been an increase in the representation of speech and language pathologists (SLPs) who use ASL, as evidenced by annual gatherings of such professionals since 2018 (See https://language1st.org/events). Due to the preponderance of ASL users in some schools for the deaf, these environments could be claimed to provide the type of language models and support from which children with developmental signed language disorder might benefit.

\subsection{The Current Case Study}

We consider the case of a deaf signing child, hereafter "Gregory", who was exposed to ASL in the home by his deaf parents, sibling, and extended family, and at school via adults and peers. In the face of robust exposure to ASL at home and at school, Gregory's production abilities in ASL did not appear as expected. He was not clear in his signing, and people often did not understand him. However, these production difficulties were not matched with language processing or comprehension challenges of similar magnitude, and Gregory's motor abilities seemed within normal ranges. The uniqueness of this case, with respect to the literature, lies in its focus on language production. Due to this, we pose 
the question of whether Gregory's language challenges could be described in terms of an expressive signed language disorder.

The report contained herein contains various types of information, including information from Gregory's mother and his school and our own linguistic and non-linguistic data collection with Gregory. All research was conducted by the two authors, who have fluency in ASL. The first author has experience working with deaf child signers of ASL and has previously published on the topic of developmental signed language disorder. The second author has experience with deaf signers of ASL and is trained to administer diagnostic instruments to hearing children suspected of being candidates for an autism spectrum disorder (ASD) diagnosis. The study was approved by the Institutional Review Board at the University of the two authors of the study, consent was obtained from Gregory's parents, and Gregory also assented to the research, in writing.

We conducted various data collection sessions with Gregory over a 27-month period, from the age of $11 ; 8$ through $13 ; 11$. Initially, he participated in a rate-of-processing study conducted in our lab (Quinto-Pozos 2016), and he returned for later sessions that focused on a case-study methodology used with children suspected of exhibiting a developmental signed language disorder (Quinto-Pozos et al. 2014). After our last session with Gregory we remained in email contact with his mother, and we received updates about his progress in school and in extra-curricular activities.

\section{Methods}

\subsection{Sources of Background Information}

We obtained a detailed medical, developmental, and educational history via an interview with Gregory's mother when he was 12;11. The interview lasted approximately $55 \mathrm{~min}$, and it was conducted in ASL by the first author. General questions for this interview included questions about childbirth, infancy, childhood, and school-age characteristics. In addition, two meetings were held at Gregory's school with language and development professionals (SLPs and a school psychologist), and notes were taken by first and second authors during those meetings. Gregory's parents also released a copy of Gregory's Psychological Evaluation Report, which was completed at his school due to ongoing concerns related to academic, social, and emotional development. Data from all of these sources allow us to provide background information that will contextualize our own work with Gregory over a period of 27 months.

\subsection{Conversational and Narrative Data}

Gregory's ASL use was filmed while conversing with the first author and while re-telling a narrative in ASL. These tasks were a subset of the tasks that children perform when administered the American Sign Language Proficiency Assessment (ASL-PA) (Maller et al. 1990). The ASL-PA protocol suggest that focal children interact informally with an adult and with a peer while being filmed. Informal questions are posed to children, such as who-among their friends-they might invite to a birthday party if there was limited capacity and where would they travel if they had the choice to go anywhere. We conducted the adult-child interview with Gregory, but did not have the opportunity to conduct the peer-child interaction since we were meeting with Gregory away from his school at that time. Additionally, Gregory retold the Tortoise and the Hare story, after viewing a cartoon version of the story with no language (speech or sign) support. Due to a lack of comparison data from a set of typically-developing DHH children, we do not provide details of Gregory's narrative production in the Results section. However, we do provide qualitative comments about his language skills during the adult-child interview, in order to provide a snapshot of his conversational abilities.

\subsection{Norm-Referenced Testing}

As part of our assessment of Gregory's signed language skills, he was administered assessments designed to examine his ASL competency and his non-linguistic reasoning. At 11;8, we administered 
the matrices subtest of the Kaufman Brief Intelligence Test-2 (KBIT-2) (Kaufman and Kaufman 2004), which is a standardized test of non-linguistic, fluid reasoning. During the same session Gregory was given the ASL Receptive Skills Test (ASL-RST) (Enns et al. 2013; Allen and Enns 2013), and at 12;1, he completed the ASL Sentence Reproduction Test (ASL-SRT), (Hauser et al. 2008; Supalla et al. 2014). In order to provide background information for the reader, details of each of these ASL assessments are provided in this section.

The ASL-RST is a test of comprehension skills in ASL used with DHH signing children between the ages of 3-12. The test was adapted from a British Sign Language (BSL) version (Herman et al. 1999), and it has been normed using data from native-signing DHH children. For the test, the child views a signed phrase/sentence on a computer (once), and then is presented with four picture choices. The child has to indicate which choice corresponds with the meaning of the signed phase/sentence; there are 45 items in total. This assessment includes constructions that test ASL comprehension skills across multiple grammatical categories, including spatial verb morphology, number/distribution, negation, size/shape specifiers, noun/verb distinctions, and handling classifiers. Children's raw scores are converted to standard scores, based on their age.

The ASL-SRT is a measure of global ASL fluency including receptive, processing, and production skills (Supalla et al. 2014; Hauser et al. 2008). Preliminary norms exist for children (beginning age 8 years) through adult age, which indicate that native signers outperform non-native signers on this test (Hauser et al. 2008; Supalla et al. 2014; Corina et al. 2020). For this assessment, test-takers view a sentence in ASL, shown on a computer screen, and are asked to repeat the sentence as faithfully as possible. They are told that every detail (signs, order of signs, use of space, specific phonological variants, etc.) should be included, to the best of their ability. Deviations from the original sentence (omissions, additions, phonological errors, etc.) are scored as incorrect. Entire sentences with no errors are awarded one point, whereas a single error results in a score of " 0 " for that sentence. Currently, the ASL-SRT is delivered using a 20-item set of sentences (Supalla et al. 2014; Corina et al. 2020), although we administer the assessment using a previous 39-item version that includes the 20 sentences in the shorter version (Hauser et al. 2008). Utilizing the longer version for case study research allows us to capture a richer data set for detailed analyses of child productions.

In addition to the ASL-SRT result obtained following the "0/1" coding scheme described above, our research lab coded each of Gregory's sign productions with a focus on multiple phonological features. This coding and analysis step allowed us to examine Gregory's sign productions in detail. The phonological features included: Dominant handshape, non-dominant handshape, path movement, hand-internal movement, place of articulation, dominant hand orientation, and non-dominant hand orientation. For each phonological feature of a target sign, we indicated whether Gregory produced the parameter (e.g., handshape) correctly and whether he matched the model's rendition of that sign's parameter. For example, if the target sign was an index point to first person (i.e., point to the chest), but Gregory produced a B-handshape instead of an extended index finger, that would be coded as "incorrect handshape" and "handshape did not meet target". However, if he produced the same target sign with an incompletely extended index finger (e.g., with bending at the finger joints), we would code that production as "correct handshape" and "handshape does not meet target". All detailed phonological coding was completed by research assistants in our lab, then every sign's coding was double-checked by the second author, and more than $50 \%$ were confirmed by the first author. 


\subsection{Fingerspelling Processing}

As noted earlier, Gregory participated in a study of rate of processing, and this occurred when he was 11;8. During that data collection session, he completed processing tasks involving ASL, fingerspelling, English reading, and non-linguistic processing. In that study, all tasks, with the exception of the fingerspelling task, were designed to assess a child's ability to quickly identify a target word (or geometric shape, in the case of the non-linguistic task) within a sequence of other signs, (ASL sentences), English words (English sentences scrolling on the screen), or non-linguistic shapes (a sequence of shapes). The stimuli were presented at slow (60\% of normal), medium (normal), and fast ( $140 \%$ of normal) rates. We include the results of the fingerspelling task in this manuscript, since it is the only task where participants had to report what the target word was (from a multiple-choice list of four words). In the other tasks, the participant only had to press a button when they would see the target word or shape (i.e., to indicate processing) in a sequence of other words or shapes. As such, the fingerspelling task is the most straightforward to interpret, with respect to a child's ability to perceive, process, remember, and identify a word that was presented to them via fingerspelling. The fingerspelled words ( $n=24$ per rate; $n=72$ total) were between $3-5$ letters in length. Among the four answer choices were: (1) the correct word, (2) a real-word distractor with a different first letter, (3) a real-word distractor with a different last letter, and (4) a nonword. Examples of the shortest and longest words include alike (distractors brave, align, and alipe) and oak (distractors irk, oar, and ork).

\subsection{Testing of Motor Skills Using a Sign-Copying Task}

We developed a test to assess Gregory's ability to reproduce sign/non-sign stimuli (Cooley and Quinto-Pozos 2017). The test was informed by the ASL sign/gesture copy task used by Poizner et al. (1984) and the British Sign Language (BSL) sign/non-sign test created by researchers from the U.K. (Marshall et al. 2006; Mann et al. 2010; Marshall and Morgan 2016). This was done to determine the status of Gregory's motor skills as applied to signed language production. For the test, we created a list of 35 ASL signs and 22 possible non-signs (actual signs from Norwegian Sign Language that contained handshapes, movements, and place of articulation phonological values that also exist in ASL) that varied in their degree of phonological complexity. Unequal numbers of signs and non-signs in our test were due to the lack of equal phonological parameter values across languages. Marshall et al. (2006) discuss sign complexity based on handshape and movement, and we included additional parameters of complexity as informed by Brentari (1998; see Appendix A for additional details). We hypothesized that ASL signs would be easier for Gregory to reproduce since they are likely to be supported by lexical access (i.e., vocabulary knowledge), and non-signs would be more difficult because they did not have such support. However, if Gregory's production difficulties were due to (or influenced by) a motor disorder, we would expect overall poor performance on copying both ASL and non-sign stimuli. Further, we expected that increased phonological complexity would add cognitive and motoric load to each sign, which would make sign copying more difficult. See Figure 1 for a schematization of performance predictions, based on domain (linguistic versus motoric) of deficit. Appendix A contains additional information about the test, including phonological features considered for complexity ratings (Table A1), a complexity rating scale (Table A2), and example signs and scoring rubric (Table A3). 


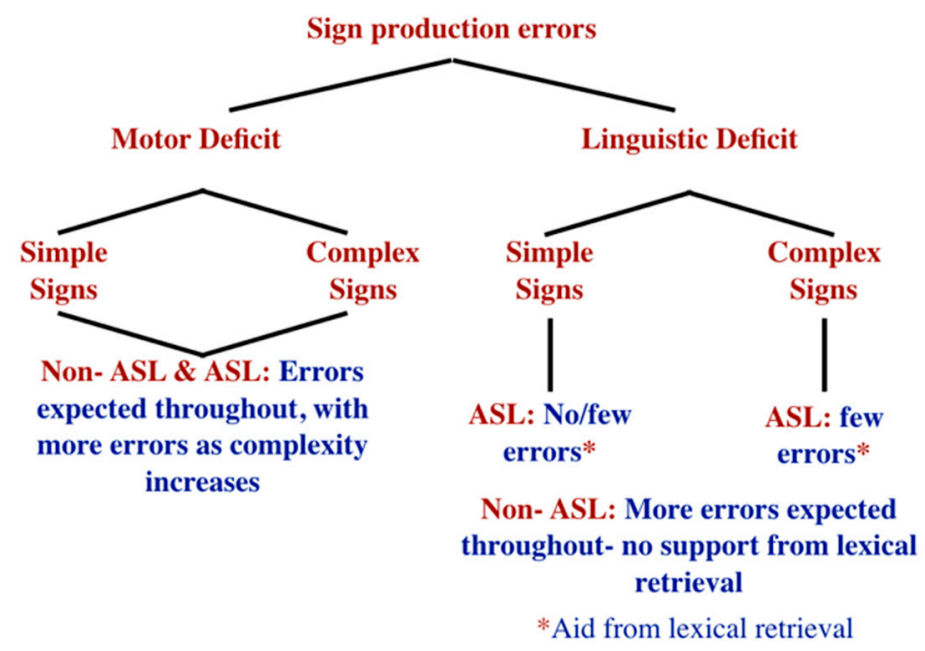

Figure 1. Predicted performance on sign/non-sign copying task, based on domain of deficit.

\section{Results}

\subsection{Background Information}

\subsubsection{Parental Interview}

According to the parental interview, Gregory's infancy and very early childhood was unremarkable; he was born full-term and there were no complications with the pregnancy or the birth, his early motor and physical development was normal, and he did not present with any behaviors in his first three years of life that would cause his family to take notice. Gregory was born to deaf, ASL-signing parents, who already had a deaf child in the home. There were many extended family members who were also ASL signers (many of whom were deaf), so Gregory was immersed in ASL from infancy. Gregory's parent could not think of any case of language or communication disorder among his extended family. Perhaps the only noticeable characteristic reported for Gregory's early development was that at age three, he seemed to exhibit a "cute style" of signing, although there were no additional descriptions about that style from his parent.

However, at four years of age, educators who worked with Gregory at school began to notice that, in his parent's words, something seemed "off". Additionally, he did not seem to be developing like other children when he was in kindergarten and first grade (approximately ages four and five, in the U.S.). It was a teacher at Gregory's school for the Deaf who first took particular notice of his signing, sharing those concerns with Gregory's parents and making them aware of apparent differences compared to other children. He wasn't picking up ASL like the other kids were, according to the educator and Gregory's parent. At that time, there was some question about whether Gregory had a learning disorder (since his emergent reading skills were not progressing as expected), and later he was also suspected of having autism spectrum disorder (more information about ASD is included below).

His mother commented on a characteristic of Gregory's communication where he had difficulty paying attention to other signers' language use, among other things. Accordingly, he was diagnosed with attention deficit disorder (ADD) at age seven, at which time he began taking medication for the condition. His mother reported that the daily medication helped tremendously, and it was particularly noticeable on days when he would not have taken his daily dose, since he had a very difficult time paying attention to adults who would try to communicate with him.

Gregory's older sibling was diagnosed with autism spectrum disorder (ASD) when Gregory was a toddler (age two). According to his mother, the sibling is an individual who is high functioning on the spectrum, although he has limited expressive communication skills. Gregory's mother reports that the sibling does use ASL, and sometimes uses it "more than Gregory does", but does not communicate as well as others around him. No one else in the family was reported as being diagnosed with ASD. 
Gregory's mother also remarked that Gregory “doesn't look like he's from a Deaf family.” His signing is different in style, and also short (generally not elaborate in his interactions with others), but also that his friends are accustomed to his style of signing. On the other hand, many adults do not seem to understand Gregory's signing, according to his mother, who characterized his signing as "sloppy". Whereas, Gregory does have a few close friends, they seem to understand him and interact with him well. His mother noted that he sometimes struggles with fingerspelling comprehension, especially if he does not know the word being produced, and he does not fingerspell much. Additionally, Gregory often experiences expressive disfluencies, which his mother described as "sign stuttering", hesitations, and repetitions. Sometimes this occurs more when he's nervous. However, when asked about Gregory's command of ASL grammatical features (e.g., pronouns, use of space, and sign inflections), his mother indicated that there didn't seem to be any issues. One comment that his mother added multiple times during the interview is that Gregory can seemingly sign clearly when he practices what he plans to sign.

Gregory's mother also provided information about school support for Gregory and his communication. As indicated, one of his teachers at school first noticed the atypicality in his signing. When he had a single instructor for multiple topics of instruction (such is the case in early schooling in the U.S.), Gregory seemed to perform better, since the instructor would know how to support his communication differences. However, he did less well when he started shifting to multiple instructors throughout the day for different topic areas, since any one of those teachers had less time with him overall and the time was distributed in short, one-hour, sessions. Gregory's mother also indicated that extra-curricular activities were very beneficial to him and his communication challenges. It was through involvement in theatrical performances and other social activities (such as off-campus trips with the school) that Gregory was able to highlight his abilities with his signing. Those activities provided him with outlets for working on his communication abilities outside of the classroom. In other words, Gregory's mother feels that he can sign clearly if he practices what he wants to say, with examples from involvement in drama activities and creating video messages that might be shared with others via social media.

\subsubsection{School Psychological Report}

When Gregory was age 10 (enrolled in 5th grade of U.S. education), a report was created by a psychologist at his school who is Deaf. This report was part of the information captured for the Individual Education Program (IEP) plan for Gregory. Essentially, the plan developed following the IEP becomes a contract between the school and a student's parents in cases where a student is receiving services based on a documented disability. The psychological report was only one part of the information submitted for the development of a plan for Gregory's IEP. Our research team was given a copy of the school psychological report regarding the consent of Gregory's parents. We include a few key points from that report here, in order to provide information from school specialists.

Gregory's issues with language (both ASL and English, although our focus in this article is on his ASL skills) were among the reasons for creating an IEP. Notably, the psychological report contained no mention of motor issues for Gregory, either with atypical use of arms/hands/fingers or legs. In fact, the report indicated that no Occupational Therapy or Physical Therapy was being recommended for Gregory, and also that no issues in motor skills were noted. However, some behavioral concerns were indicated in the report that raised the question of whether Gregory was a candidate for an Autism Spectrum Disorder (ASD) diagnosis.

The school psychological report also contained a separate signed language evaluation by an ASL Specialist who is Deaf, which yielded various notable comments about Gregory's signing. This report indicated that he demonstrated vocabulary knowledge that was broad in nature along with good use of ASL grammatical features, including the use of numeral incorporation on signs and the use of non-manual features such as headshake and head nod for negation and affirmation. He was also reported to use ASL classifiers and other sentential features, such as rhetorical-question structures 
and negation at the end of sentences. However, the evaluator commented on Gregory's seeming overuse of the sign AND, which according to the report, was affirmed by his parents and described as a placeholder, as he thought about what to say next. The ASL Specialist did not comment on particular difficulties understanding Gregory, although that professional did indicate that he appeared stiff and uncomfortable in his use of signed language. No other information relevant to motor processes and the use of hands and arms was included.

The results of three tests of nonverbal abilities from the school psychological report are provided here, since they provide complementary information to the testing that was performed in our own research lab. The standardized tests were: the Wechsler Nonverbal Scale of Ability (WNV; Wechsler and Naglieri 2006), the Wechsler Intelligence Scale for Children, Fourth Edition (WISC-IV; Kaufman et al. 2006), and the Differential Abilities Scale-II (DAS-II; Saulnier 2013). Here, we point out some of the main results, in order for the reader to have a more complete picture of Gregory's strengths and weaknesses. A mix of average performance or above, along with below average performance, characterize the results from the standardized tests. Gregory scored below average in performance in tests of working memory (WISC-IV), verbal abilities (DAS-II), and processing speed (WISC-IV), which was only slightly below average. On the other hand, Gregory scored in the average (or above average) range on the majority of tests (the DAS-II General Conceptual Ability subtest, Nonverbal Reasoning Abilities Cluster, Spatial Abilities Cluster, and Special Nonverbal Composite; WNV Full Scale Score and Spatial Span subtest), including two where he scored in the Superior range (WNV Matrices and Picture Arrangement). The summary from the school psychologist indicated that the testing of Gregory's cognitive and intellectual skills suggested average-range performance along with strong skills working on tasks that involve visual aids, pictures, or objects that he is able to manipulate. The report also indicated that Gregory was able to replicate designs and determine patterns with concepts or objects.

In order to address the suspicion of ASD as a possible diagnosis for Gregory, his school administered two assessments that are used to examine children's profiles, the Gilliam Autism Rating Scale, Second Edition (GARS-2) and the Childhood Autism Rating Scale, Second Edition (CARS-2). The results of the GARS-2 indicated that Gregory's parents' ratings resulted in a profile that suggested that ASD is Unlikely for Gregory, whereas teachers, counselors, and SLP responses were in the Possibly to Very Likely range. From the CARS-2, the results indicated that Gregory demonstrated mild-to-moderate symptoms of ASD. In addition to these results, an independent assessment (two sessions totaling $90 \mathrm{~min}$ ) was conducted by an expert in childhood autism among Deaf signing children. Based on tests of social skills, non-verbal reasoning, language, and perspective taking, the expert reported that Gregory did not demonstrate any indicators consistent with ASD. No positive diagnosis for ASD resulted from any of these assessments.

\subsection{Data Collected from Gregory}

Our team met with Gregory from age 11;8 to 13;11. and we report data from conversational and narrative tasks, norm-referenced testing (such as language comprehension and sentence repetition, fingerspelling processing, and motoric functioning using a sign/non-sign copying task). Gregory's mother reported his hearing as $70 \mathrm{~dB}-90 \mathrm{~dB}$ loss in both ears, which in the profoundly deaf range, and he uses no assistive listening devices (hearing aids, cochlear implants, etc.). Gregory's deafness is congenital, and he generally does not use his voice to produce spoken English.

\subsubsection{Conversational Task}

The adult-child interview lasted $23 \mathrm{~min}, 30 \mathrm{~s}$. Gregory seemed comfortable and chatted easily with the first author in ASL. He did not appear distressed or anxious, and was open and discussed topics ranging from sports to theater to hypothetical scenarios, such as who to invite to a party and what he would do if he won the lottery. Despite his apparent comfort chatting, Gregory's signing was not particularly fluid. He often hesitated, as if unsure of what to say next, and he repeated some signs, such 
as the sign THEN. Various phonological features of Gregory's signs were also atypical. Most notably, Gregory often failed to produce target handshapes with either his dominant or non-dominant hand. His non-dominant hand (left hand) is sometimes not included in two-handed signs, and when it is produced, he tends to hold it lower in the signing space than his dominant hand.

\subsubsection{Norm-Referenced Testing}

On the KBIT-2 Matrices subtest, Gregory's performance yielded a Standard Score of 119. This is more than one standard deviation above the mean for his age, putting him above average in non-linguistic fluid reasoning. In relation to language comprehension, on the ASL Receptive Skills Test (ASL-RST), Gregory's Standard Score = 106, which is in the average range for his age.

For the sentence repetition task (ASL-RST), which tests both comprehension and production, Gregory's score on the 20-item version of the test was 5, which is more than $-2 S D$ below the mean for native signers ages $10-14(\mathrm{M}=13.7, S D=3.2)$. This performance indicates that Gregory's language skills could be considered to be impaired as compared to other deaf native signers approximately the same age. However, since a sentence-reproduction test requires both comprehension and production abilities, we also report the percentage of signs across the 20 sentences that Gregory attempted. Out of 97 signs (across all sentences), Gregory produced 86 of those signs (88.7\%), 5 omissions (5\%), and 2 additions $(2 \%)$.

A detailed phonological analysis of each of Gregory's signs, in comparison with the target model's signs, reveals a richer picture of his language-production tendencies. In the analysis that focuses on whether Gregory was producing the correct phonological value, he ranged between $77.5 \%$ and $91.4 \%$ correct across all parameters, with handshape (especially non-dominant handshape) being the most difficult for Gregory to produce correctly. Alternatively, place of articulation was produced the most accurately of all parameters (91.4\%). Gregory's performance was lower considering whether he produced a phonological value just as the model did in the assessment's stimuli, with a range of $58.3 \%$ to $86.9 \%$ of meeting the target (i.e., matching the form) of the model. See Table 1 for averages for all coded parameters.

Table 1. ASL-SRT percent correct for phonological parameters.

\begin{tabular}{ccc}
\hline Parameter & Correct/Incorrect (\%) & Meets Target (\%) \\
\hline Handshape-dominant hand & 85.11 & 68.09 \\
Handshape-non-dominant hand & 77.55 & 58.33 \\
Path movement & 85.56 & 73.91 \\
Hand-internal and wrist movement & 84.62 & 76.92 \\
Place of articulation & 91.49 & 85.11 \\
Orientation-dominant hand & 89.36 & 78.72 \\
Orientation-non-dominant hand & 86.96 & 86.96 \\
\hline
\end{tabular}

Various other details of Gregory's productions for the ASL-SRT are useful for contextualizing his performance. Perhaps most obvious during the phonological coding was that Gregory sometimes fails to use his non-dominant hand correctly during his signing. In some cases, a two-handed sign is articulated with only his dominant hand, or his non-dominant hand is oriented incorrectly (as in the sign NEWSPAPER, shown in Figure 2, which represents Gregory's signs copied by an adult deaf signer who served as a model for the photos). Other examples show a pattern of failing to meet a target handshape of a sign (e.g., he would produce a handshape requiring extended fingers without full extension). For example, his non-dominant hand would often appear to be in a relaxed 5-handshape position, rather than with full extension of all five fingers, which can also be seen in the sign NEWSPAPER (although, in that sign his non-dominant is also oriented incorrectly). In YEAR (also in Figure 2), Gregory's transition from a number seven handshape to the handshape for YEAR (to represent '7-years') included extension of the index through pinky fingers, which is not what one 
would expect in that transition. Note, also the final dominant-hand handshape for YEAR, which is not as fully formed (i.e., not a full S-handshape) as one might expect. Finally, the sign for MARRY in Figure 2 depicts an incorrect target with respect to both handshape and contact location for the end of the sign. We did not code for contact location, which means that his errors may be underreported, based on our analysis.

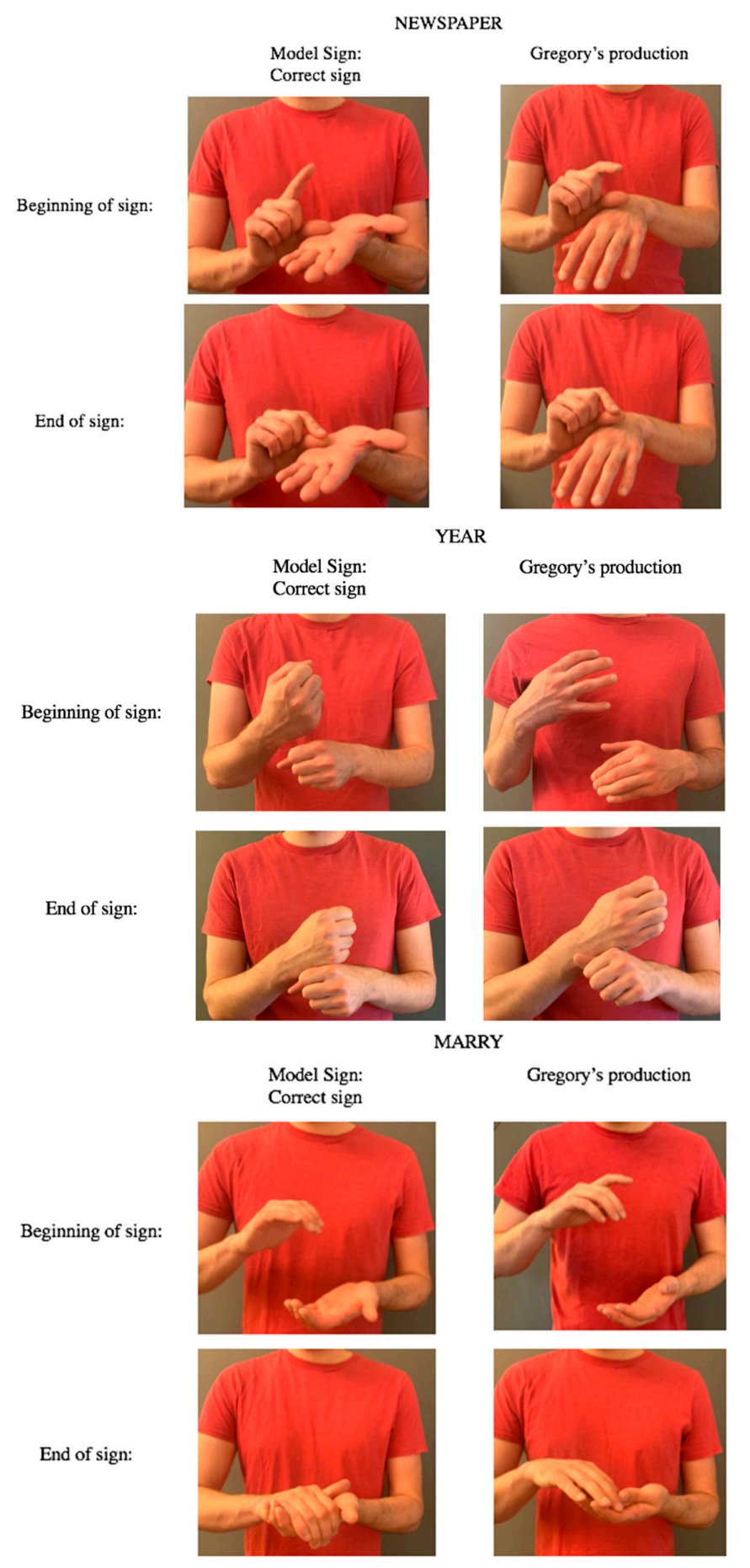

Figure 2. Examples of ASL-SRT stimuli signs versus Gregory's productions.

Overall, a combination of a few omissions and additions, along with multiple examples of Gregory articulating phonological targets differently than the ASL stimulus model resulted in a score that is considered impaired performance on the ASL-SRT. He did not regularly fail to produce individual signs 
in sentences, and he seemed to comprehend the stimulus sentences well. There also did not appear to be any issues with memory, other than the sentences that became increasingly lengthy towards the end of the assessment. It was overwhelmingly clear from this assessment that Gregory's phonological productions are not what one would expect, at least not in the case of a test of language production that is not rehearsed and relies on one's language competence for comprehension and retelling.

\subsubsection{Fingerspelling Processing}

Gregory completed a fingerspelling task as part of a rate-of-processing study when he was 11;8. Since the results of this task have not been reported previously, we include the results of an age-matched group of typically-developing DHH children who are also signers of ASL ( $\mathrm{n}=9$; mean age: 11;4, range 8;11-13;3). Gregory scored a total 91.7\% correct across all rates (slow, medium, fast; total of 72 words, 6 incorrect). The comparison group scored 90.6\% correct $(\mathrm{SD}=29.2 \%)$. Gregory's errors were distributed among the slow $(n=4)$, medium $(n=1)$, and fast $(n=1)$ rates.

\subsubsection{Assessing Motoric Functioning}

The second author visited Gregory at his school to administer the sign/non-sign copy task when he was 13;11. As noted in an earlier section, each copied item (either sign or non-sign) was evaluated on a 0-1 scale. Correctly copied tokens were assigned a score of 1 . Items with only one of three incorrect features (location, movement, or handshape) received a score of 0.5 . An assignment of a 0 indicates that the token had errors on two or more features. Of 57 total tokens, Gregory correctly copied 46. See Table 2 for a distribution of errors.

Table 2. Gregory's (only) errors on the sign and non-sign copy task.

\begin{tabular}{cccc}
\hline Token & Category & Complexity & Score \\
\hline TEACHER & Sign & 1 & 0 \\
non-sign11 & Non-sign & 2 & 0.5 \\
REFER & Sign & 4 & 0.5 \\
non-sign22 & Non-sign & 5 & 0.5 \\
HOMEWORK & Sign & 5 & 0.5 \\
non-sign20 & Non-sign & 4 & 0.5 \\
non-sign19 & Non-sign & 4 & 0.5 \\
HELICOPTER & Sign & 2 & 0.5 \\
non-sign15 & Non-sign & 4 & 0.5 \\
\hline
\end{tabular}

Gregory had a total of 9 errors (4 signs and 5 non-signs), which represents $15 \%$ of the total test items. Phonological complexity seemed to play some role, since one-half of his incorrectly-copied items had a complexity score of " 4 " or greater. Even so, his only failed token has a complexity rating of " 1 ".

\subsection{Characterizing Gregory's Home and School Environment}

As part of this report, we feel that it is useful to provide information about his home and school environment, with an eye on the types of linguistic experiences and support structures that he is exposed to in those settings. Information in this section comes from parental reports (both within the interview and via informal discussions with parents outside of the formal interview). It has been made clear that Gregory's parents are extremely supportive of his development and his success. It was one of Gregory's parents who contacted the first author, in order to explore research and rehabilitation options for Gregory, which reveals their desire to positively affect his linguistic development and his performance in school.

Throughout his entire life, Gregory attended schools for the Deaf that specialize in educating deaf and hard of hearing children with signed language as the core component of language and learning. As noted in the report about the interview with Gregory's mother, it was an educator at a school for the Deaf who first noticed that Gregory's language skills were not as one would expect for a native-signing 
child. That individual - and others since then-worked with Gregory to help improve his language skills. Additionally, we joined in meetings at Gregory's school that included speech and language pathologists, the school psychologist, and others who are familiar with Gregory and his communication abilities. These meetings were designed to discuss Gregory's performance and behavior in school. It was clear to us that professionals at the school were very aware of Gregory's deficits, and they were also supportive in helping him to improve.

Over his school years Gregory has participated in various extra-curricular events. He has been very involved in drama and theatre, with regular participation in annual school performances. According to Gregory's mother, this involvement has been very positive for Gregory, since it has given him the opportunity to express himself. He has been given speaking lines in the theatrical performances, to which he responds with much preparation and practice, according to his mother.

Beyond his participation in drama and theatre, Gregory has been involved with school trips and some sports activities. He has also been known to respond to national queries for video-based competitions with practiced submissions that are viewed by members of the Deaf community throughout the U.S. Gregory's mother also noted that he enjoys playing video games with his friends, which suggests that he engages in peer interaction regularly, at least to a certain extent.

\section{Discussion}

This case study provides a snapshot of "Gregory", a young adolescent who is a native signer of ASL and presents with an expressive language disorder. Despite his language-production challenges, Gregory interacts with ASL signers on a daily basis. He is surrounded by fluent signers of ASL at home and at school, and, to an extent, within the larger community (i.e., outside of school functions). We begin with a review of his production deficit following our analysis of data that we have collected, and then we turn to a discussion of his community and contextualization of his communication deficits, within the context of his daily life.

Gregory's production problems were identified by his parents and educators at the bilingual (ASL-English) school that he attended. The importance of detail in these cases cannot be overstated. It has been previously reported (e.g., Quinto-Pozos et al. 2011) that potential cases of developmental signed language disorders in deaf children are often not given substantial attention, since a common belief of parents and educators is that the children might grow out of their struggles in time. Even in the case of Gregory, the first notice of his atypicality was not made evident until about the age of four, at which time both parents and educators tried to determine how to best understand his struggles. Without a timely diagnosis, precious developmental time can be lost, and children might not be provided with the types of intervention and support structures that they need in order to improve.

A question that had been raised by professionals at his school is whether Gregory was a good candidate for an ASD diagnosis. During the period in which we worked with Gregory, no positive diagnosis had been made, although multiple assessments indicated that mild-to-moderate symptoms were present. Even so, an independent expert who assessed Gregory concluded that his language skills were not representative of those of other deaf children with whom he had worked (e.g., issues with perspective-taking skills, correct orientation of signs, etc.). In our analysis of Gregory's language production, we did not identify the manner of production issues that Shield et al. (2017) identified in their sample of DHH children with ASD and dyspraxia, and Gregory did not have atypical comprehension abilities (either on the ASL-RST or on a fingerspelling comprehension task we administered), which was a common feature of the language abilities of the DHH children in the Shield et al. study (Bhat et al. 2017). Having these points in mind, even if Gregory had been diagnosed as high functioning on the autism spectrum during the time we worked with him, the question of how to best characterize (and diagnose) his language production problems would have remained.

Based on the data that we collected and analyzed from Gregory, we have determined that he presents with average to above-average non-verbal intelligence, average language processing and comprehension abilities, but below average language production abilities. The analysis we performed 
of his sentence-reproduction abilities reveals the struggles he has with producing clear and fully-formed target signs, even though he is able to reproduce nearly $90 \%$ of the signs in the test sentences. As such, he does not generally have difficulties with everyday language processing and comprehension, which is also supported by his performance on a normed test of ASL comprehension and the fingerspelling task that he completed as part of a rate-of-processing study from our lab. In addition, we show how Gregory engaged in conversation with us during our scheduled meetings, without expressing concern about language comprehension, and the same was reported by the ASL Specialist at his school (as reported in the school psychological report). However, it is clear that his language production abilities are atypical; using the ASL-SRT as a tool for analysis, one could suggest that his production abilities are impaired.

The atypicality of Gregory's language problems do not appear to be caused by a motor impairment. First, there were no reports from his mother about motor problems (even when asked about that specifically during interview) nor from Gregory's school, such as in the school psychological report or in the meetings we held with school personnel. In fact, the school psychologist reported that no motor issues were evident with Gregory. Perhaps the only comment about fluency/fluidity that arose was from the Deaf ASL Specialist who indicated that Gregory seemed awkward (stiff, uncomfortable). Unfortunately, we did not seek external evaluation of his motor skills by a physical or occupational therapist, which we recognize, could have provided further evidence to consider. However, we do have independent (anecdotal) evidence of his manual skills from his mother, who reports that Gregory loves to draw, and she feels he is quite talented and detailed in his work. Our own data collection using a sign/non-sign copying task (Poizner et al. 1984) revealed no pervasive issues with producing stimuli signs that were presented to him over the course of the task. We should note that Gregory was given a purposeful task: to copy the sign/non-sign ("gesture") as faithfully as possible. His ability to reproduce the vast majority of the forms without any problem suggest that Gregory is not suffering from a motor disorder. As such, our assessment is that the atypicality of Gregory's sign productions is not related to, nor caused by, a motor deficit. Gregory can coordinate his sign articulators (i.e., his fingers, hands, and arms). Evidently, Gregory needs to purposefully focus on language production clarity in order to produce sign targets (handshapes, movements, etc.) in a typical fashion.

In addition, in this manuscript we have provided a snapshot of Gregory's rich linguistic environment, which we believe, serves to support him communicatively beyond what his underlying deficits might predict. Despite the atypicality of his language production, Gregory's mother reports that his involvement in extra-curricular activities at school has been extensive. Based on periodical communication with Gregory's mother we know that he continued to be active in drama and off-campus travels with his classmates and teachers, even after we met with him for data collection sessions. This involvement highlights the support that he receives regularly from his signing peers, teachers, and other adults in the academic community. We believe that such support may have moderated Gregory's level of functional impairment over time. Admittedly, this suggestion is only speculative given the lack of specific details about Gregory's language input at school and in the community, and also details how that input may have affected Gregory's communication difficulties. While, we do not have specific details about improvements that Gregory may have made over time, our occasional communication with his mother reveals that he continues to involve himself in various activities at school. Based on the our data collection, what seems evidently clear is that Gregory can manage many of his daily conversations, and adults (and various peers) appear to have strategies for interacting with him.

Even in the face of an impairment of expressive language, Gregory is able to express himself enough (and is encouraged to do so continuously) that his social development appears to still be supported throughout his school years. We would assume that his impairment does not interfere, in great part, with his daily living and independent functioning. However, it likely does interfere with his academic development, as evidenced by parental and educational staff concerns. Our focus has 
been on Gregory's ASL development, since he is a native-signer of the language, but much could also be learned by looking closely at his English abilities, which are beyond the scope of the present work.

The case of Gregory provides evidence that not all native-signing children produce signed language without production issues. In fact, it is the case that a developmental disorder of signed language production can be present for a deaf signer who has been exposed to a signed language since birth, even though their comprehension/processing and motor abilities appear to be within normal ranges. Gregory's case also implies that non-native signers (i.e., those exposed to a signed language sometime after birth) could also demonstrate such a deficit.

Clearly, what remains is the very important job of developing language intervention protocols that can be used with such signers with a DLD. This means that schools that serve signing DHH children could benefit greatly from language intervention professionals who are fluent in signed language. In the U.S., this means that more professionally-certified SLPs who sign ASL are required, and ideally more SLPs who are trained in developmental signed language disorders. We also need more Deaf language specialists who can help to diagnose and provide much needed language input for such children. Advances in theory and descriptions of DLDs in signing DHH children could help us to become better prepared to serve students like Gregory, in order for them to overcome linguistic challenges and become successful in their lives.

Author Contributions: Conceptualization, D.Q.-P. (80\%) and F.C. (20\%); Data curation, D.Q.-P. (60\%) and F.C. $(40 \%)$; Formal analysis, D.Q.-P. (70\%) and F.C. (30\%); Funding acquisition, D.Q.-P. (100\%); Investigation, D.Q.-P. and F.C. (50\% each); Methodology, D.Q.-P. and F.C.(80\%) and F.C. (20\%); Project administration, D.Q.-P. (80\%) and F.C. (20\%); Resources, D.Q.-P. (70\%) and F.C. (30\%); Software, D.Q.-P. (80\%) and F.C. (20\%); Supervision, D.Q.-P. $(80 \%)$ and F.C. (20\%); Validation, D.Q.-P. ( $80 \%)$ and F.C. $(20 \%)$. Visualization, D.Q.-P. (70\%) and F.C. (30\%); Writing-original draft, D.Q.-P. (90\%) and F.C. (10\%); Writing-review \& editing, D.Q.-P. (80\%) and F.C. (20\%). All authors have read and agreed to the published version of the manuscript.

Funding: This research received no external funding.

Acknowledgments: We thank Gregory and his family for their willingness to take part in this study; their involvement has constituted a fundamental part of advancing scientific knowledge about developmental signed language disorders. We also are very appreciative of the educators and language and developmental specialists at Gregory's school who provided valuable information that complemented our own data collection. Additionally, we thank Drew Warren for serving as a sign model for the sign examples pictured in the article. Any errors or oversights are our own.

Conflicts of Interest: The authors declare no conflict of interest.

\section{Appendix A. Details of the Sign/Non-Sign Copying Task Developed for Assessing Linguistic and Motor Skills}

Our approach for measuring sign production for the task rates aspects of each stimulus sign as simple or complex, using a number of sign features informed by (Battison[1978] 2003; Brentari 1998). For the task we build on examples from Poizner et al. (1984) and colleagues from the U.K. (Marshall et al. 2006; Mann et al. 2010). Our design takes into account 1- versus 2-handed signs, compound signs, handshape changes, core versus non-core handshapes, movement types, and handshape symmetry in two-handed signs. This design was described in a poster presentation at the Deaf and Hard of Hearing SRCD pre-Conference Workshop in 2017 (Cooley and Quinto-Pozos 2017), and, we thank colleagues for feedback on the presented version of this task. See Table A1 for descriptions and examples, Table A2 for our rating scale, and Table A3 for example complexity scores based on ASL signs.

Each stimulus sign in the task (total = 57 signs, 35 ASL signs \& 22 non-signs) is coded for level of complexity based on the components of sign production in Table A1, and values are assigned based on complexity: "0" for simple, "1" for complex. See Table A2 for a rubric for assigning complexity values. 
Table A1. Sign features considered for complexity rating on sign copying task.

\begin{tabular}{|c|c|}
\hline Feature & Description \\
\hline \multicolumn{2}{|l|}{ One-handed signs } \\
\hline Compound sign & $\begin{array}{l}\text { Simple: a monomorphemic, non-compound sign } \\
\text { Complex: a monomorphemic sign that reflects the combination of two other signs } \\
\text { (e.g., HOME + WORK = HOMEWORK) }\end{array}$ \\
\hline Handshape change & $\begin{array}{l}\text { Simple: no change } \\
\text { Complex: a single sign in which there exists more than one handshape during the } \\
\text { production of the sign }\end{array}$ \\
\hline Core handshape & $\begin{array}{c}\text { Simple: signs with one of the five most common ASL handshapes- 1/G, A, B, C, O, S, } 5 \\
\text { Complex: signs utilizing any other ASL handshape }\end{array}$ \\
\hline Movement & $\begin{array}{l}\text { Simple: only internal or path movement } \\
\text { Complex: internal and path movement }\end{array}$ \\
\hline \multicolumn{2}{|l|}{ Two-handed signs } \\
\hline Handshape symmetry & $\begin{array}{l}\text { Simple: both hands have the same handshape throughout production } \\
\text { Complex: hands have different handshapes }\end{array}$ \\
\hline
\end{tabular}

Table A2. Sign-copying task complexity rating scale.

\begin{tabular}{|c|c|c|c|c|c|c|}
\hline & & Compound Sign & Handshape Change & Core Handshape & Movement & Handshape Symmetry \\
\hline \multirow[t]{2}{*}{ 1-handed } & Simple & No +0 & No +0 & Yes +0 & $\begin{array}{c}\text { Internal or path } \\
\text { movement }+0\end{array}$ & N/A \\
\hline & Complex & Yes +1 & Yes +1 & $\mathrm{No}+1$ & $\begin{array}{l}\text { Internal plus path } \\
\text { movement }+1\end{array}$ & N/A \\
\hline \multirow[t]{2}{*}{ 2-handed } & Simple & No +0 & $\mathrm{No}+0$ & Yes +0 & $\begin{array}{c}\text { Internal or path } \\
\text { movement }+0\end{array}$ & Yes +0 \\
\hline & Complex & Yes +1 & Yes +1 & $\mathrm{No}+1$ & $\begin{array}{l}\text { Internal plus path } \\
\text { movement }+1\end{array}$ & No +1 \\
\hline
\end{tabular}

Each sign receives a summed rating of 0-4 (one-handed signs) or 0-5 (two-handed signs). See Table A3.

Table A3. Sign-copying task complexity score examples.

\begin{tabular}{ccccccc}
\hline ASL Sign & Total Score & Compound Sign & Handshape Change & Core Handshape & MovementHandshape Symmetry \\
\hline LOOK-LIKE & 4 & 1 & 1 & 1 & 1 & N/A \\
BEAUTIFUL & 3 & 0 & 1 & 0 & 0 & N/A \\
OPPOSITE & 0 & 0 & 0 & 0 & 0 & 0 \\
HOMEWORK & 4 & 1 & 1 & 0 & 1 & 0 \\
ESTABLISH & 2 & 0 & 0 &
\end{tabular}

\section{References}

Allen, Thomas, and Charlotte Enns. 2013. A psychometric study of the ASL Receptive Skills Test when administered to Deaf 3, 4, and 5-year-old children. Sign Language Studies 14: 58-79. [CrossRef]

Battison, Robbin. 2003. Lexical borrowing in American Sign Language. Silver Spring: Linstok Press. First published 1978.

Bhat, Anjana N., Sudha M. Srinivasan, Colleen Woxholdt, and Aaron Shield. 2017. Differences in praxis performance and receptive language during fingerspelling between deaf children with and without autism spectrum disorder. Autism 22: 1-12. [CrossRef] [PubMed]

Bishop, Dorothy V. M., Margaret J. Snowling, Paul A. Thompson, Trisha Greenhalgh, and CATALISE-2 Consortium. 2017. Phase 2 of CATALISE: A multinational and multidisciplinary Delphi consensus study of problems with language development: Terminology. Journal of Child Psychology and Psychiatry 58: 1068-80. [CrossRef] [PubMed]

Bishop, Dorothy. 2017. Why is it so hard to reach agreement on terminology? The case of development language disorder (DLD). International Journal of Language \& Communication Disorders 52: 671-80.

Brentari, Diane. 1998. A Prosodic Model of Sign Language Phonology. London: The MIT Press.

Conti-Ramsden, Gina, and Anne Kesketh. 2003. Risk markers for SLI: A study of young language-learning children. International Journal of Language \& Communication Disorders 38: 251-63. 
Cooley, Frances, and David Quinto-Pozos. 2017. Motor or Language Disorder? Development of a Test for Apraxia in Deaf Signers. In Proceedings of the Deaf and Hard of Hearing SRCD pre-Conference, Poster presentation. Austin, TX, USA, April 5.

Corina, David P., Lucinda Farnady, Todd LaMarr, Svenna Pedersen, Laurel Lawyer, Kurt Winsler, Gregory Hickok, and Ursula Bellugi. 2020. Effects of age on American Sign Language sentence repetition. Psychology and Aging 35: 529-35. [CrossRef] [PubMed]

Denmark, Tanya, Joanna Atkinson, Ruth Campbell, and John Swettenham. 2014. How do typically developing deaf children and deaf children with autism spectrum disorder use the face when comprehending emotional facial expressions in British Sign Language? Journal of Autism Developmental Disorders 44: 2584-92. [CrossRef]

Denmark, Tanya. 2011. Do Deaf Children with Autism Spectrum Disorder Show Deficits in the Comprehension and Production of Emotional and Linguistic Facial Expressions in British Sign Language? Ph.D. Thesis, University College London, London, UK.

Enns, Charlotte J., Kyra Zimmer, Patrick Boudreault, Sarah Rabu, and Cheryle Broszeit. 2013. American Sign Language: Receptive Skills Test. Winnipeg: Northern Signs Research, Inc.

Hauser, Peter C., Raylene Paludnevičiene, Ted Supalla, and Daphne Bavelier. 2008. American Sign Language-Sentence Reproduction Test: Development and implications. In Sign Language: Spinning and Unraveling the Past, Present and Future. Edited by Ronice Muller de Quadros. Petropolis: Editora Arara Azul, pp. 160-72.

Herman, Ros, Katherine Rowley, Kathryn Mason, and Gary Morgan. 2014. Deficits in narrative abilities in child British Sign Language users with specific language impairment. International Journal of Language $\mathcal{E}$ Communication Disorders 49: 343-53.

Herman, Ros, Sallie Holmes, and Bencie Woll. 1999. Assessing BSL Development: Receptive Skills Test. Lake Forest: Forest Bookshop.

Kaufman, Alan S., and Nadeen L. Kaufman. 2004. KBIT2: Kaufman Brief Intelligence Test. San Antonio: Pearson/PsychCorp.

Kaufman, Alan S., Dawn P. Flanagan, Vincent C. Alfonso, and Jennifer T. Mascolo. 2006. Test Review: Wechsler Intelligence Scale for Children, Fourth Edition (WISC-IV). Journal of Psychoeducational Assessment 24: 278-95. [CrossRef]

Kelley, Lauren, and James McCann. 2020. Sign Language Intervention with a Deaf, Signing Child with Suspected Specific Language Impairment. Paper presented at Speech-Language-Hearing Association of Virginia Conference, Herndon, VA, USA, March 11-14.

Maller, Susan J., Jenny L. Singleton, Samuel J. Supalla, and Tina Wix. 1990. The Development and Psychometric Properties of the American Sign Language Proficiency Assessment (ASL-PA). Journal of Deaf Studies and Deaf Education 4: 249-69. [CrossRef]

Mann, Wolfgang, Chloë R. Marshall, Kathryn Mason, and Gary Morgan. 2010. The acquisition of sign language: The impact of phonetic complexity on phonology. Language, Learning, and Development 6: 60-86. [CrossRef]

Marshall, C. Chloë R., Kate Rowley, Kathryn Mason, Ross Herman, and Gary Morgan. 2013. Lexical organisation in deaf children who use British Sign Language: Evidence from a semantic fluency task. Journal of Child Language 40: 193-220. [CrossRef]

Marshall, Chloë R., Kathryn Mason, Kate Rowley, Ross Herman, Joanna Atkinson, Bencie Woll, and Gary Morgan. 2015. Sentence repetition in deaf children with specific language impairment in British Sign Language. Language Learning and Development 11: 237-51. [CrossRef]

Marshall, Chloë R., Tanya Denmark, and Gary Morgan. 2006. Investigating the underlying causes of SLI: A non-sign repetition test in British Sign Language. Advances in Speech-Language Pathology 8: 347-55. [CrossRef]

Marshall, Chloë, and Gary Morgan. 2016. Investigating sign language development, delay, and disorder in Deaf children. In The Oxford Handbook of Deaf Studies in Language. Edited by Marc Marschark and Patricia E. Spencer. Oxford: Oxford University Press, pp. 1-17. [CrossRef]

Mason, Kathryn, Kate Rowley, Chloe R. Marshall, Joanna R. Atkinson, Ross Herman, Bencie Woll, and Gary Morgan. 2010. Identifying specific language impairment in deaf children acquiring British Sign Language: Implications for theory and practice. British Journal of Developmental Psychology 28: 33-49. [CrossRef] 
Meier, Richard P. 2006. The form of early signs: Explaining signing children's articulatory development. In Advances in the Sign Language Development of Deaf Children. Edited by Brenda Schick, Marc Marschark and Patricia E. Spencer. Oxford: Oxford University Press, pp. 202-30.

Morgan, Gary, Ross Herman, and Bencie Woll. 2007. Language impairments in sign language: Breakthroughs and puzzles. International Journal of Language and Communication Disorders 42: 97-105. [CrossRef] [PubMed]

Poizner, Howard, Ursula Bellugi, and Vicente Iragui. 1984. Apraxia and Aphasia for a visual-gestural language. American Journal of Physiology 246: 868-83. [CrossRef]

Quinto-Pozos, David, Anjali Forber-Pratt, and Jenny Singleton. 2011. Do developmental signed language disorders exist? Perspectives from professionals. Language, Speech, and Hearing Services in Schools 42: 1-21. [CrossRef]

Quinto-Pozos, David, Jenny L. Singleton, and Peter C. Hauser. 2017. A case of specific language impairment in a deaf signer of American Sign Language. Journal of Deaf Studies and Deaf Education 22: 204-18. [CrossRef]

Quinto-Pozos, David, Jenny Singleton, Peter Hauser, and Susan Levine. 2014. A case-study approach to investigating developmental signed language disorders. In Multilingual Aspects of Signed Language Communication and Disorder. Edited by D. Quinto-Pozos. Bristol: Multilingual Matters, LTD, pp. 70-89.

Quinto-Pozos, David, Jenny Singleton, Peter Hauser, Susan Levine, Carrie Lou Garberoglio, and Lynn Hou. 2013. Atypical signed language development: A case study of challenges with visual-spatial processing. Cognitive Neuropsychology 30: 332-59. [CrossRef]

Quinto-Pozos, David. 2016. Rates of visual processing and (a)typical acquisition. Paper presented at Theoretical Issues in Sign Language Research (TISLR), Melbourne, Australia, January 4-7.

Saulnier, Celine A. 2013. Differential Ability Scales (DAS and DAS-II). In Encyclopedia of Autism Spectrum Disorders. Edited by Fred R. Volkmar. New York: Springer.

Shield, Aaron, and Richard P. Meier. 2012. Palm reversal errors in native-signing children with autism. Journal of Communication Disorders 45: 439-54. [CrossRef] [PubMed]

Shield, Aaron, Krista Knapke, Morgan Henry, Sudha Srinivasan, and Anjana Bhat. 2017. Impaired praxis in gesture imitation by deaf children with autism spectrum disorder. Autism Developmental Language Impairments 2: 1-14. [CrossRef]

Shield, Aaron, Richard P. Meier, and Helen Tager-Flusberg. 2015. The use of sign language pronouns by native-signing children with autism. Journal of Autism Developmental Disorders 45: 2128-45. [CrossRef] [PubMed]

Suggs, Trudy. 2018. Deaf Schools: TRUE-BUSINESS Deaf?-20 Years Later. Available online: http://www. trudysuggs.com/deaf-schools-true-business-deaf-20-years-later/ (accessed on 20 September 2020).

Supalla, Ted, Peter C. Hauser, and Daphne Bavelier. 2014. Reproducing American Sign Language sentences: Cognitive scaffolding in working memory. Frontiers in Psychology 8. [CrossRef] [PubMed]

Wechsler, David, and Jack A. Naglieri. 2006. Wechsler Nonverbal Scale of Ability Administration and Scoring Manual. San Antonio: Pearson.

Woll, Bencie, and Gary Morgan. 2012. Language impairments in the development of sign: Do they reside in a specific modality or are they modality-independent deficits? Bilingualism Language and Cognition 15: 75-87. [CrossRef]

Publisher's Note: MDPI stays neutral with regard to jurisdictional claims in published maps and institutional affiliations.

(C) 2020 by the authors. Licensee MDPI, Basel, Switzerland. This article is an open access article distributed under the terms and conditions of the Creative Commons Attribution (CC BY) license (http://creativecommons.org/licenses/by/4.0/). 